\title{
Central-Tapped Node Linked Modular Fault Tolerance Topology for SRM Applications
}

\author{
Yihua Hu, Member IEEE, Chun Gan, Student Member, IEEE, \\ Wenping Cao, Senior Member, IEEE, Wuhua Li, Member IEEE, Stephen Finney
}

\begin{abstract}
Electric vehicles (EVs) and hybrid electric vehicles (HEVs) can reduce greenhouse gas emissions while switched reluctance motor (SRM) is one of the promising motor for such applications. This paper presents a novel SRM fault diagnosis and fault tolerance operation solution. Based on the traditional asymmetric half-bridge topology for SRM driving, the central tapped winding of SRM in modular half bridge configuration are introduced to provide fault diagnosis and fault tolerance functions, which are set idle in normal conditions. The fault diagnosis can be achieved by detecting the characteristic of the excitation and demagnetization currents. An SRM fault tolerance operation strategy is also realized by the proposed topology, which compensates for the missing phase torque under the open-circuit fault, and reduces the unbalanced phase current under the short-circuit fault due to the uncontrolled faulty phase. Furthermore, the current sensor placement strategy is also discussed to give two placement methods for low cost or modular structure. Simulation results in Matlab/Simulink and experiments on a $750 \mathrm{~W}$ SRM validate the effectiveness of the proposed strategy, which may have significant implications and improve the reliability of EVs/HEVs.
\end{abstract}

Index Terms - Central tapped node, electric vehicles, fault diagnosis, fault tolerance, SRM, traction drives.

\section{NOMENCLATURE}

$\begin{array}{ll}D & \text { PWM duty-cycle } \\ i_{\mathrm{a}}, i_{\mathrm{b}}, i_{\mathrm{c}} & \text { Currents for phases A, B and C } \\ i_{\max } & \text { Phase current peak when } \\ & \text { faulted } \\ i_{\max } & \text { Phase current peak when } \\ & \text { normal } \\ \triangle_{i} & \text { Hysteresis window } \\ N_{\mathrm{r}} & \text { Rotor poles } \\ K_{\mathrm{L}} & \text { Inductance slope when normal }\end{array}$

Manuscript received September 29, 2014; revised December 7, 2014 and January 28, 2015; accepted March 09, 2015. This work is sponsored by the EPSRC of UK (EP/L00089X/1).

Copyright $\odot 2010$ IEEE. Personal use of this material is permitted. However, permission to use this material for any other purposes must be obtained from the IEEE by sending a request to pubs-permissions@ieee.org.

Y. Hu is with the College of Electrical Engineering, Zhejiang University, Hangzhou, 310027, China; and the Department of Electronic and Electrical Engineering, University of Strathclyde, Glasgow, U.K.

C. Gan and W. Li are with the College of Electrical Engineering, Zhejiang University, Hangzhou 310027, China (e-mail: ganchun.cumt@163.com).

W. Cao is with the School of Electronics, Electrical Engineering and Computer Science, Queen's University Belfast, Belfast, U.K.

S. Finney is with the Department of Electronic and Electrical Engineering, University of Strathclyde, Glasgow, UK.

$\begin{array}{ll}K_{\mathrm{i}}{ }^{\prime} & \text { Current slope when normal } \\ K_{\mathrm{L}}{ }^{\prime} & \text { Inductance slope when faulted } \\ K_{\mathrm{i}} & \text { Current slope when faulted } \\ L_{\mathrm{min}} & \begin{array}{l}\text { Minimum of the phase } \\ \text { inductance }\end{array} \\ L_{\mathrm{max}} & \begin{array}{l}\text { Maximum of the phase } \\ \text { inductance }\end{array} \\ T^{*} & \text { Given load torque } \\ T & \text { Instantaneous torque } \\ T_{\mathrm{av}} & \text { Average electromagnetic } \\ & \begin{array}{l}\text { torque of one phase when } \\ \text { normal }\end{array} \\ T_{\mathrm{av}}{ }^{\prime} & \text { Average electromagnetic } \\ & \text { torque of one phase when } \\ & \text { faulted } \\ U_{\text {in }} & \text { Bus voltage } \\ \omega_{r} & \text { Angular velocity } \\ \theta_{\text {on }} & \text { Turn-on angle } \\ \theta_{\text {off }} & \text { Turn-off angle }\end{array}$

\section{INTRODUCTION}

Currently, electric vehicles (EVs) and hybrid electric vehicles (HEVs) provide a low-pollution and high-efficiency solution to the depletion of fossil fuels and environmental problems, and thus are under wide development across the world [1], [2]. Switched reluctance motors (SRMs) are becoming a mature technology for EV/HEV applications and are also considered to have commercial potentials for massive global markets due to their non-reliance on rare earth materials and a wide torque-speed range, in addition to their robust mechanical structure, low cost and high efficiency [3]-[7]. For EV/HEV applications, high reliability and fault tolerance is critically important as they involve human lives.

The SRM drive system is mainly composed by two parts: power electronics and motors [8]. For EV/HEV applications, the switching devices are prone to failure, especially in harsh environments such as vehicular conditions [9]. Based on the widely used asymmetrical half-bridge drive topology, the power electronics faulty conditions such as short-circuits and open-circuits are studied in [10]-[16]. In [11], the bus current is employed to distinguish open-circuit faults and short-circuit faults in power electronics converters. In [12], two on-line fault diagnosis methods based on analysis of bus current or freewheeling current are developed to distinguish short-circuits and open-circuits. In [13], the switching device fault diagnosis 
including open-circuit and short-circuit is achieved by analysis of phase current without additional hardware investment. The FFT algorithm is also introduced to analyze the power converter supply current of phase absence fault in [14]. A method to predict the SRM drive performance under normal and fault operating conditions is proposed in [15], which uses a genetic algorithm based artificial neural networks, showing a fast and accurate prediction. In [16], a fuzzy inference system is employed to characterize the SRM drives under normal and fault operations. The other research field is motor fault diagnosis. The winding short-circuit and open-circuit are the common faults in electric machines [17]. Pole short and few turns shorted of phase winding are discussed in [18]. In [19], injecting high-frequency diagnostic pulses to the motor windings is proposed to locate faulty phase and categorise the fault type.

In order to improve the SRM fault tolerance ability, hardware and software can be employed to achieve fault tolerance operation. For fault tolerance control, artificial neural network, genetic algorithms, and the time dynamic models are developed for normal and abnormal condition control of SRM [20]. Fuzzy controller without a model is proposed in [21] to improve the faulty performance of SRM. For hardware improvement, multi-phase SRM is developed to improve fault tolerance [22], [23]. The axial-flux configuration based, five-phase SRM is developed for EV application [23]. In order to improve the reliability of the SRM driving system, dual-channel SRM is developed and fault tolerance strategy is also discussed in [24]. Modular stator SRM is proposed in [25], which is convenient for replacing the fault winding. In [26], a double-layer-per-phase isolated SRM is also investigated which can not only improve the fault-tolerant capability, but also achieve higher torque and low noise. Furthermore, segmental stator SRM with modular construction is proposed for fault tolerance application [27]. In [28], two extra switching devices are added in the traditional asymmetric half bridge topology for an 8/6 SRM drive system to decrease the impact of a fault. However, the proposed fault tolerance topology is without module structure and only accustoms limited fault condition. A decentralized phase driving topology is developed in [29] to make full use of independence of phase windings; while a lot of half asymmetric modular. In the absence of position sensors, a fault tolerance control strategy is proposed in [30] to deal with the absent phase operation. In [31], a fault tolerance scheme is proposed for the SRM drive that driven by a three-phase bridge inverter when the phase windings are connected in star. The fault characteristics of the SRM drive under short and open circuit fault operations are analyzed in details in [32], and a fault tolerant control method is presented. However, the phase absence operation in open circuit condition, and setting the turn-off angle advanced in short circuit condition still causes a large torque ripples.

Although hardware and software fault tolerance have been developed, the hardware changes the driving topology of SRM or design the new structure of SRM that limits the wide application. Furthermore, by software, the fault diagnosis and fault tolerance operation can be achieved without changing the traditional SRM drive topology; but the fault diagnosis method is complex and fault toleration can be realized in limited fault condition. So, we need the fault diagnosis and fault tolerance strategy is equipped with the following characteristics:

(1) No/little change to the traditional SRM drive topology;

(2) Easy fault diagnosis and fault tolerance operation at extreme fault conditions;

(3) Modular structure and convenient for industrial applications.

In this paper, in order to satisfy the mentioned requirements, a new modular fault tolerance topology is proposed on the basis of the traditional SRM driving topology; and the corresponding fault diagnosis and fault tolerance schemes are proposed by trade-off hardware and software. The paper is organized as follows: Section II describes the proposed fault tolerance topology, and fault diagnosis method. Section III builds the mathematical model of SRM under fault tolerance condition and gives the fault tolerance control strategy. Section IV discusses the current sensors placement. Section V presents experimental results and their analysis, followed by the conclusions in Section VI.

\section{FAUlt Diagnosis TOPOLOGY AND STRATEGY}

New techniques are developed to improve the system performance under various faults, including switching device faults, phase winding and short-circuit faults. The fault tolerant strategy is to make changes to hardware as little as possible on the basis of the traditional SRM topology.

\section{A. Proposed Fault Tolerance Topology}

Traditionally, the SRM phase windings are composed of an even number of series connected windings, as shown in Fig.1. Thus, central-tapped windings are formed which can be easily designed in $8 / 6$ or 12/8 SRM. Fig.2 shows the traditional 12/8 SRM winding connection, in which $L_{a 1}, L_{a 2}, L_{a 3}$, and $L_{a 4}$ represent for four windings of one SRM phase; the central tapped node A of phase $L_{a}$ is developed as shown in Fig. 2. One phase of SRM drive circuit is composed by traditional asymmetrical half-bridge topology and phase winding; the whole circuit can be divided into two parts: left part and right part; each part has the same components, including diode, switching device and phase winding. The two parts have the characteristics of axial symmetry that can be employed in fault tolerance operation. When the central tapped node is connected with positive node of power supply source, the left part of the converter is bypassed that can block the left part fault. The same method, when the central tapped node A is connected with negative node of power supply source, the right part of the converter is bypassed that can block the fault from right part.

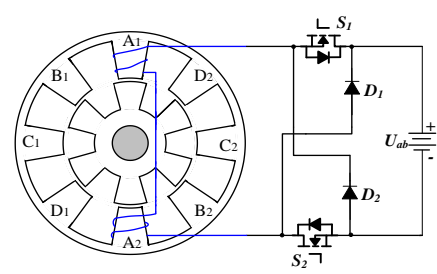

(a) 8/6 SRM

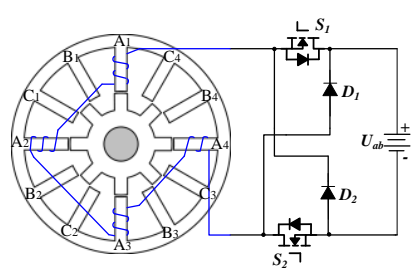

(b) 12/8 SRM
Fig. 1. Basic winding structure of SRM. 


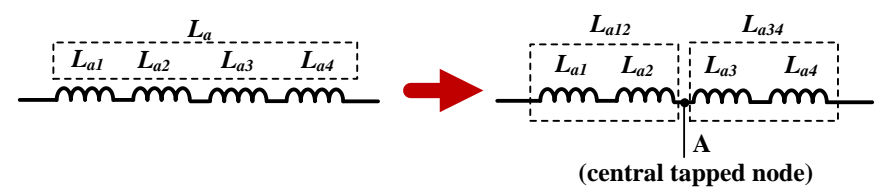

Fig. 2. Central-tapped winding of a 12/8 SRM.

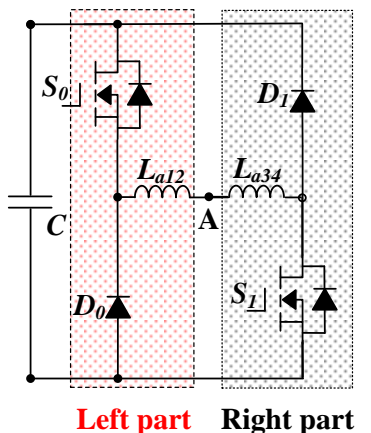

Fig. 3. Two parts of phase converter.

On the basis of the central tapped node and axial symmetry characteristics of the traditional drive topology, the proposed fault tolerance topology is presented in Fig.4. Fig. 4(a) is the main driving topology composed by main topology (traditional asymmetrical half bridge) as Fig. 4(b), and fault tolerance module as Fig. 4(c). The fault tolerance module is the traditional three-phase half-bridge modular. The half-bridge central nodes are connected with central tapped node of phase windings, which are A, B and $\mathrm{C}$ respectively. Three-phase half-bridge is employed to approach fault tolerance operation. The proposed topology has the characteristics of modular structure; on the base of traditional asymmetrical half-bridge topology, only one three-phase bridge modular is needed. The basic structure of SRM is almost not changed. In normal conditions, the proposed topology works as traditional asymmetrical half bridge topology; the fault tolerance module is in idle condition that makes the proposed converter has the same efficiency as the traditional asymmetrical half bridge topology. The fault tolerance module works only at fault condition.

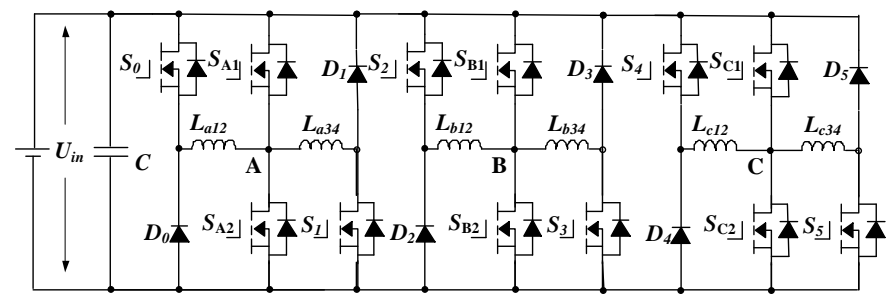

(a) Proposed fault tolerance topology

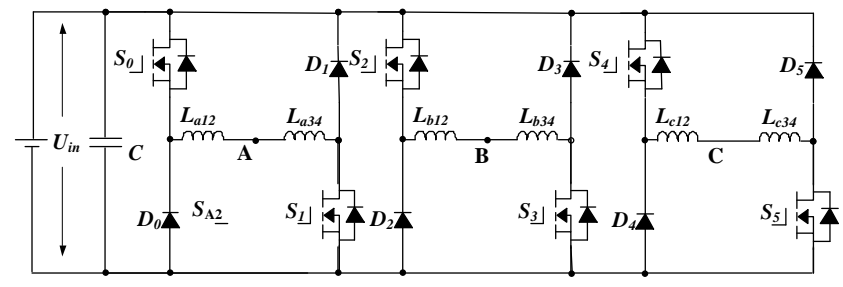

(b) Main topology for SRM

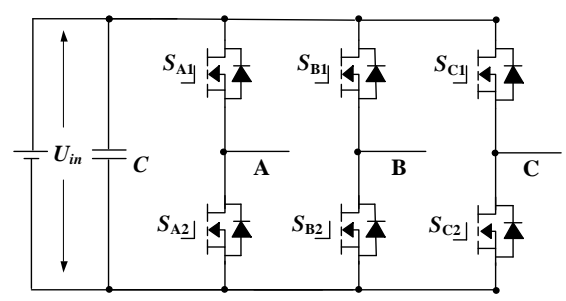

(c) Fault tolerance module

Fig. 4. Proposed topology for SRM fault tolerance operation.

\section{B. Switching Device Faults and Phase Winding Open-Circuit} Faults

Switching device faults and phase winding open-circuit faults are common fault phenomena. In the traditional asymmetrical half-bridge converter, there are two switching devices for each phase; and each phase have four windings for a $12 / 8$ SRM. When there is no current in the excitation region in phase $L_{a}$ that means the open-circuit occurs. The diagnosis needs to locate which part is under fault condition by replacing $S_{0}$ by $S_{A I}$, and giving the turn-off single to $S_{0}$. In the right part of the converter, $S_{A l}, S_{A 2}, D_{l}, S_{1}$ and $L_{a 34}$ compose a new asymmetrical half-bridge. In the right part asymmetrical half-bridge, if the faulty phase can work that proves the left part of converter is under fault condition. By the same method, replacing $S_{1}$ by $S_{A 2}$, and giving the turn-off single to $S_{1}$; in left part of converter, $S_{0}, S_{A 1}, S_{A 2}, D_{0}$ and $L_{a 12}$ compose a new asymmetrical half-bridge. In the left part asymmetrical half-bridge, if the faulty phase can work that proves the right part of the converter is under fault condition. The diagnosis flowchart of the open-circuit fault is shown in Fig. 5.

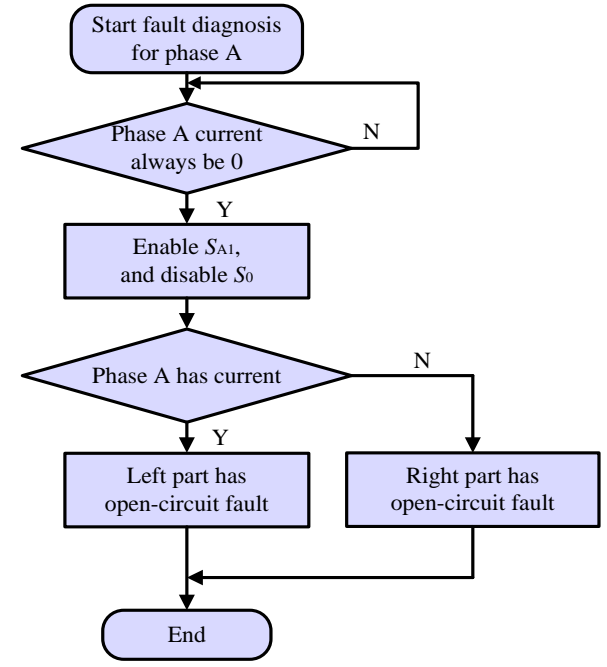

Fig. 5. Flowchart for the diagnosis of the open circuit fault.

\section{Fault Tolerance Operation under Open-Circuit Fault Conditions}

When a faulty part is identified in the faulty phase, the fault tolerance module and main topology combines new topology for faulty phase converter. If the left part of one phase converter is in fault condition, in the fault tolerance topology, the left part of one phase converter, including the switching device $S_{0}$, diode $D_{0}$ and phase winding $L_{a 12}$, is shorted by half-bridge $S_{A 1}$ and $S_{A 2}$ to block faulty part. Fig. $6\left(\right.$ a) is the typical example of $S_{0}$ under open-circuit condition. When open-circuit fault occurs, the half-bridge $S_{A 1}$ and $S_{A 2}$ is activated to combine with right part 
converter to form a new fault tolerance topology. In the new formed fault tolerance operation topology, when $S_{A I}$ and $S_{I}$ conduct, the excitation circuit is shown in Fig. 6(b). Fig. 6(c) presents the energy recycling mode, in which the winding voltage is $-U_{\text {in }}$ to speed up winding demagnetization. Fig. 6(d) shows the freewheeling conduction mode, in which the winding voltage is 0 . The working modes of the fault tolerance converter are the same as a traditional converter, except only a half phase winding taking part in working.

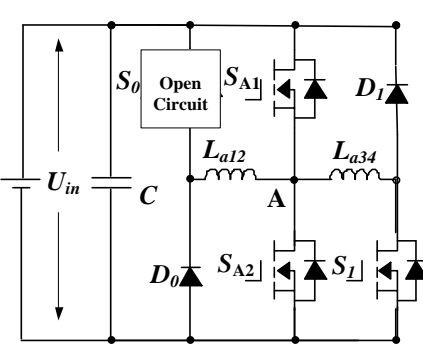

(a) Upper switch open circuit

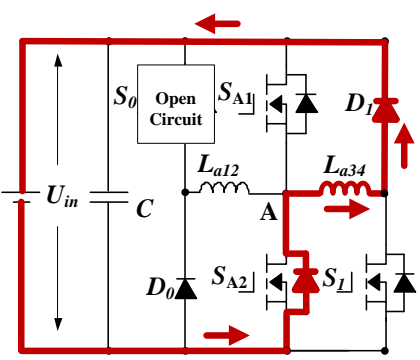

(c) Energy recycling mode Fig. 6. Fault tolerance operation topology under open-circuit condition.

The same fault tolerance operation can be achieved, when $D_{0}$ or $L_{a 12}$ is faulty. When the right part of one phase converter is under open-circuit fault condition, the left part of one phase converter and fault tolerance module can combined to form a new fault tolerance topology, the same method as Fig. 6.

\section{Switching Device and Phase Winding Short-Circuit Fault Diagnosis}

When switching device $S_{0}$ is short-circuited, the only freewheeling mode is illustrated in Fig.7 (a); when the short-circuit fault of switching device $S_{l}$ occurs, the only freewheeling mode is illustrated in Fig.7 (b); Both in Fig.7 (a) and (b) fault condition, the corresponding phase current is always over zero that can be employed in short-circuit fault diagnosis.

When a short-circuit fault is detected, the next step is to locate which switching devices is under fault condition. For example, if $S_{0}$ has a short-circuit fault, $S_{A l}$ is enabled by giving drive signals to replace $S_{0}$. The right part of converter and half-bridge compose a new asymmetrical half bridge. In the right part asymmetrical half-bridge, if the freewheeling current can decrease to zero; the faulty part can be located in $S_{0}$; the right part converter and half bridge can form a new converter to achieve fault tolerance operation that is the same as open-circuit. The diagnosis flowchart of the short-circuit fault is shown in Fig. 7(c).

The left part of the converter and half-bridge compose a new asymmetrical half-bridge. In the left part asymmetrical half-bridge, if the freewheeling current can decrease to zero; the faulty part can be located in $S_{l}$; the left part converter and half-bridge can form a new converter to achieve fault tolerance operation that is the same as open-circuit.

For instance, when the switching device $S_{0}$ is short-circuited, the half bridge arm and right part converter form new topology. In order to block the faulty part, switching devices $S_{I}$ is employed as chopping devices. In excitation and freewheeling state, due to $S_{A I}$ conducting, the both sides of phase winding $L_{a 12}$ share the same electric potential that prevent the current forming in $L_{a 12}$; in energy recycle mode, there is no current loop for $L_{a 12}$. Therefore, in the three basic working states, there is no current in phase winding $L_{a l 2}$, as presented in Fig.8 (a) (c), which proofs left part converter is blocked. Similarly, when switching device $S_{l}$ is in short-circuit condition; in order to block the right part converter, $S_{0}$ is employed as chopping switching device.

Inner turn short-circuit faults are also the faults to cause the decreasing of phase inductance; but the faulty phase still can operate. The proposed fault tolerance strategy also can bypass the short-circuited part to stop it from propagating.

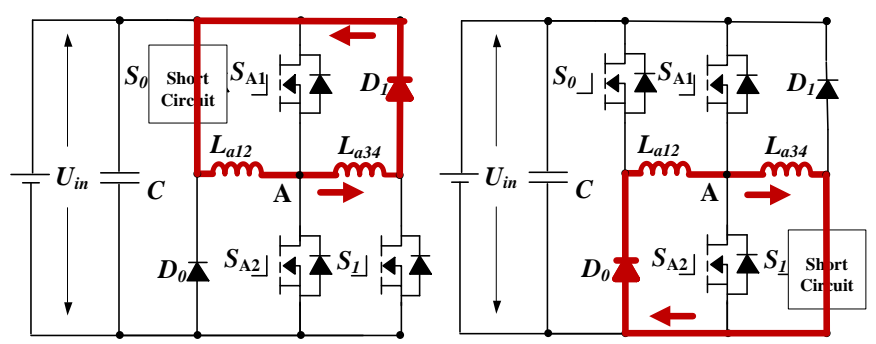

(a) $S_{0}$ short-circuit

(b) $S_{1}$ short-circuit

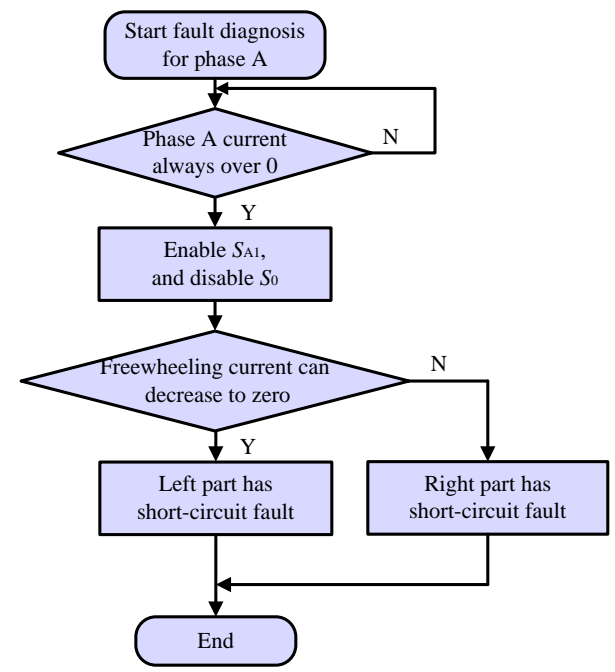

(c) Diagnosis flowchart of the short-circuit fault Fig. 7. Diagnosis of switching device short-circuits

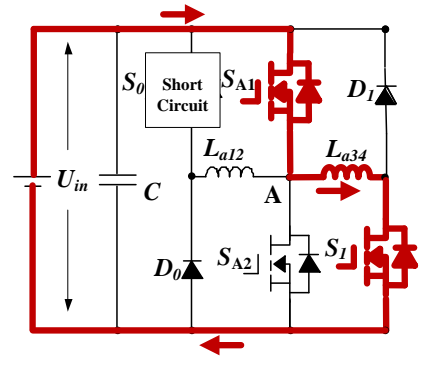

(a) Excitation circuit

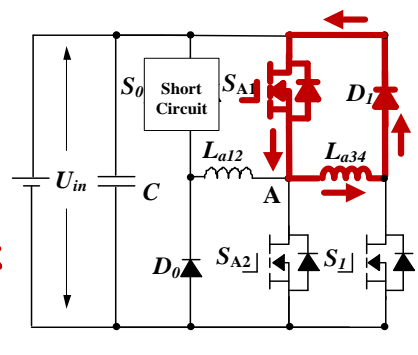

(b) Freewheeling conduction mode 


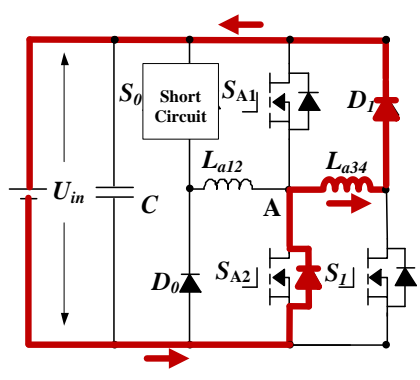

(c) Energy recycling mode

Fig. 8 Fault tolerance operation under $S_{0}$ short circuit condition

\section{FAult TOLERANCE OPERATION CONTROL STRATEGY}

After locating a fault part, the corresponding fault tolerance control strategy is needed to deal with the faulty condition, as described in the following section.

\section{A. Control Schemes for SR Drives}

Broadly speaking, there are mainly two methods: current chopping control (CCC) and voltage-PWM control, while many variations exist on the two basic schemes. The drive circuit is assumed to be the same for both schemes. A closed-loop, speed-controlled SRM drive with voltage-PWM regulation scheme and current regulation scheme are shown in Fig. 9. The speed error is processed though a speed controller, such as a proportional integral (PI) controller. The motor speed is obtained from a speed calculator using an encoder to detect the rotor position. The turn-on and turn-off angles are determined by the position detector to control the phase commutation. However, for the system safety, the fault protection part is provided to deal with the drive failure, such as IGBT faults and phase winding faults in the converter.

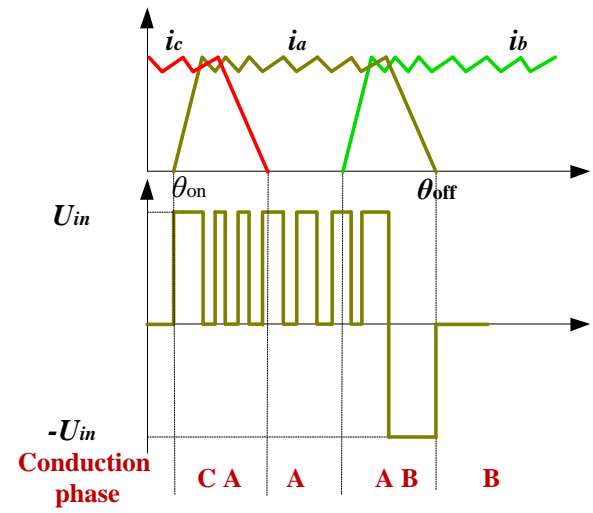

(a) Conduction phase sequence

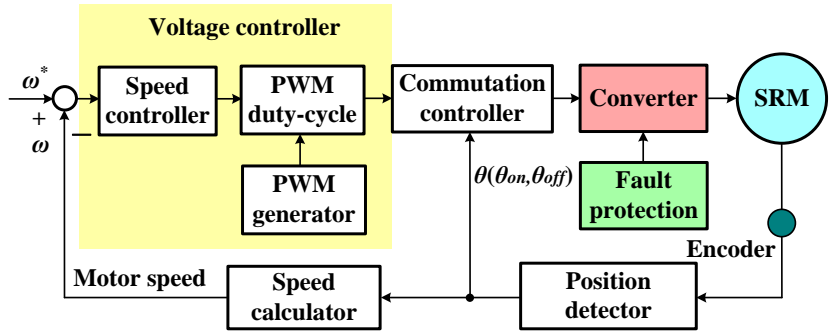

(b) Diagram of voltage-PWM control system

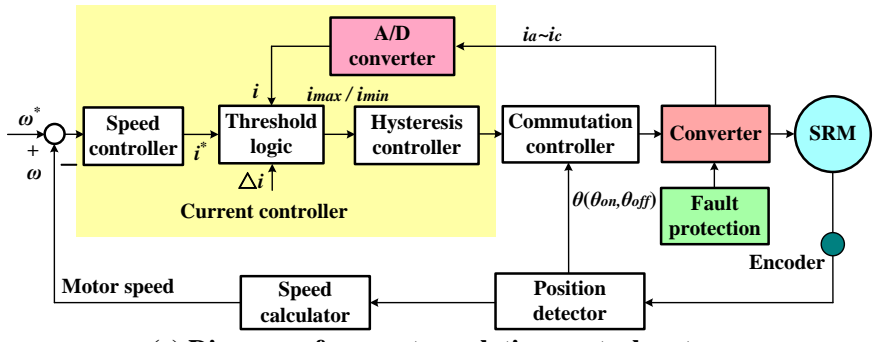

(c) Diagram of current regulation control system Fig. 9. SRM control strategy

In SRM driving, the switching sequence is decided by phase conduction sequence. The phase conduction sequence of the SRM adopts a six-step mode as phases A-AB-B-BC-C-CA, as shown in Fig. 9 (a). In Fig. 9(b), the phase voltage is the control issue, which is addressed by a voltage controller. The PWM duty-cycle is regulated by a PWM generator according to the instantaneous speed, without current regulation. The current waveform has its natural shape at all speeds, as though the supply voltage is chopped down to the value $D U_{\text {in }}$ with a duty-cycle $D$. In Fig. 9 (c), the phase current is the control issue, which is regulated by a current controller. The instantaneous phase currents, $i$, are measured using the current sensors installed in the phase windings, and fed back to the threshold logic. The current command is added and subtracted from the threshold logic with a hysteresis window, $\triangle i$, to obtain the $i_{\max }$ and $i_{\min }$ that determine the switching state of the phase in each turn-on region.

\section{B. Characteristics of the Drive under the Fault Tolerance Condition}

Fig. 10 shows the relationship between phase current and phase inductance. As illustrated in the figure, $\theta_{\text {on }}$ and $\theta_{\text {off }}$ are the turn-on and turn-off angles, respectively, $i_{1}$ and $L_{1}$ are the phase current and phase inductance under the normal conditions, $i_{2}$ and $L_{2}$ are under the fault tolerance conditions, and $i_{4}$ and $i_{5}$ are the phase currents when the turn-on angle is set lagging behind. Fig. 10 (a) shows the phase current and phase inductance in the fault tolerance operation with a half phase winding, compared to a normal operation; Fig. 10 (b) shows the phase current operates in fault tolerance conditions when the turn-on angle is set lagging behind.

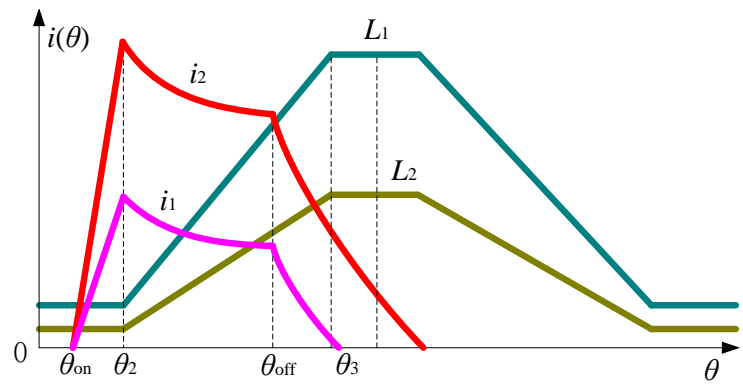

(a) Fault tolerance operation with a half phase winding 


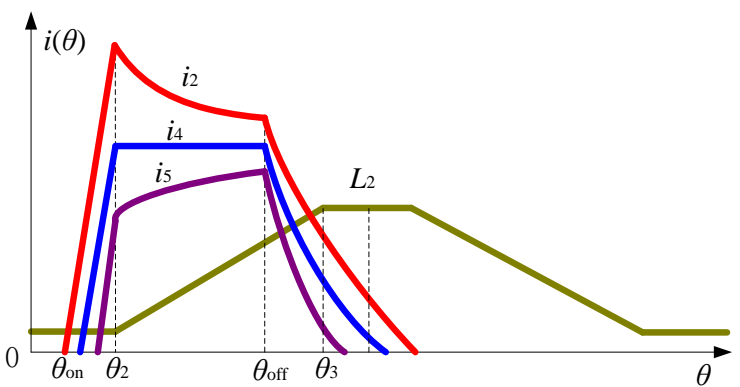

(b) Turn-on angle lagging behind

Fig. 10. Relationship between the phase current and phase inductance.

The phase inductance slope factor in the inductance ascending region is expressed as

$$
K_{L}=\frac{L_{\max }-L_{\min }}{\theta_{3}-\theta_{2}}
$$

where $L_{\min }$ and $L_{\max }$ are the minimum and maximum of the phase inductance, and $\theta_{2}$ and $\theta_{3}$ are the corresponding rotor position.

In the region of $\theta_{\mathrm{on}} \leq \theta<\theta_{2}$, the phase current is expressed as

$$
i(\theta)=\frac{U_{\text {in }}}{\omega_{r}} \frac{\theta-\theta_{\text {on }}}{L_{\text {min }}}
$$

where $U_{\text {in }}$ is the bus voltage, and $\omega_{r}$ is the angular velocity. In this region, the phase current goes up quickly, following the current slope factor $K_{i}$, given by

$$
K_{i}=\frac{d i}{d \theta}=\frac{U_{\text {in }}}{\omega_{r} L_{\text {min }}}>0
$$

In the region of $\theta_{2} \leq \theta<\theta_{\text {off }}$, the phase current is expressed as

$$
i(\theta)=\frac{U_{\text {in }}}{\omega_{r}} \frac{\theta-\theta_{\text {on }}}{L_{\min }+K_{L}\left(\theta-\theta_{2}\right)}
$$

The peak value of the phase current is at the position $\theta=\theta_{2}$, which is given by

$$
i_{\text {max }}=\frac{U_{\text {in }}}{\omega_{r}} \frac{\theta_{2}-\theta_{\text {on }}}{L_{\min }}
$$

The average electromagnetic torque of one phase is given by

$$
T_{a v}=\frac{N_{r}}{2 \pi} \frac{U_{\text {in }}^{2}}{\omega_{r}^{2}}\left(\theta_{\text {off }}-\theta_{2}\right)\left(\frac{\theta_{2}-\theta_{o n}}{L_{\min }}-\frac{1}{2} \frac{\theta_{\text {off }}-\theta_{2}}{L_{\max }-L_{\min }}\right)
$$

where $N_{\mathrm{r}}$ is the rotor poles.

If the motor system has an open-circuit or short-circuit fault in the converter, the proposed converter will operate with a half part of the fault phase winding, then

$$
\left\{\begin{array}{l}
L_{\max }{ }^{\prime}=\frac{1}{2} L_{\max } \\
L_{\min }{ }^{\prime}=\frac{1}{2} L_{\min }
\end{array}\right.
$$

where $L_{\min }{ }^{\prime}$ and $L_{\max }{ }^{\prime}$ are the minimum and maximum of the faulty phase inductance.

The phase inductance slope factor in the inductance ascending region in the fault-tolerant operation is as follows

$$
K_{L}{ }^{\prime}=\frac{1}{2} \frac{L_{\max }{ }^{\prime}-L_{\text {min }}{ }^{\prime}}{\beta_{s}}=\frac{1}{2} K_{L}
$$

In the region of $\theta_{\mathrm{on}} \leq \theta<\theta_{2}$, the phase current slope in fault-tolerant operation is as follows

$$
K_{i}^{\prime}=\left(\frac{d i}{d \theta}\right)^{\prime}=\frac{U_{\text {in }}}{\omega_{r} \frac{1}{2} L_{\min }}=\frac{2 U_{\text {in }}}{\omega_{r} L_{\min }}=2 K_{i}
$$

The peak value of the phase current at the position $\theta=\theta_{2}$, in fault-tolerant operation, is

$$
i_{\text {max }}{ }^{\prime}=\frac{U_{\text {in }}}{\omega_{r}} \frac{\theta_{2}-\theta_{\text {on }}}{\frac{1}{2} L_{\min }}=\frac{U_{\text {in }}}{\omega_{r}} \frac{2\left(\theta_{2}-\theta_{\text {on }}\right)}{L_{\min }}=2 i_{\text {max }}
$$

The average electromagnetic torque of the failure phase is given by

$T_{a v}{ }^{\prime}=\frac{N_{r}}{2 \pi} \frac{U_{i n}{ }^{2}}{\omega_{r}^{2}}\left(\theta_{o f f}-\theta_{2}\right)\left(\frac{\theta_{2}-\theta_{o n}}{\frac{1}{2} L_{\min }}-\frac{1}{2} \cdot \frac{\theta_{o f f}-\theta_{2}}{\frac{1}{2} L_{\max }-\frac{1}{2} L_{\min }}\right)=2 T_{a v}$

According to Eqs (10) and (11), the peak value of the phase current, and the average electromagnetic torque of the failure phase are double of the normal value when working in fault-tolerant operation. However, in a closed-loop system, the total average electromagnetic torque is the same as that in the normal state, due to a constant load.

When an open-circuit fault of the drive happens, conventionally, the system still works in the phase absence operation to ensure the continued working ability in a closed-loop system. However, the currents of other normal phases will be larger than the previous one to compensate the torque output, due to the adjustment of the speed controller. The unbalanced phase current increases the torque ripple and the load capacity also is reduced considerably. When the short-circuit fault of the drive happens, the demagnetization current cannot decrease to zero due to a zero-voltage loop, which causes phase current more unbalanced and obviously increases the torque ripple.

Considering the proposed fault tolerance scheme in the $\mathrm{CCC}$ system, a half of the failure phase still can be put into use to ensure the torque output. Since the phase current is the control target, it will be regulated to the same reference compared to the normal one, even though a half of the failure phase is removed. In voltage-PWM control strategy, the phase voltage is the control target. The imposed voltage on each phase is the same, no matter the phase winding works in a whole part or half part. In order to reduce the unbalanced phase current further in voltage-PWM system, the turn-on angle of the failure phase can be adjusted lagging behind to reduce the increased phase current in the failure winding, as illustrated in Fig. 10 (b). Hence, the proposed drive topology can be used to compensate the current and torque, and reduce the torque ripple to improve the drive performance in fault conditions.

\section{Comparison of the Proposed Fault Tolerance Operation with Other Strategies}

In the traditional fault tolerance strategy, the defective-phase-operation also can be achieved. In a worse fault condition, such as all upper switching devices $\left(S_{0}, S_{2}, S_{4}\right)$ are broken, the SRM cannot work. By the proposed fault tolerance strategy, the topology still can operate under extreme faulty conditions. The proposed topology can support one of switching devices in each phase converter under fault condition. 
In extreme faulty operation condition, only one switching of main driving topology is healthy. The proposed fault tolerance strategy still can sustain the SRM operation. As the illustrated in Fig. 11, only left part of phase $L_{a}$ converter is healthy; the $S_{0}$, $S_{A 1}, S_{A 2}$ and $D_{0}$ compose a new topology that can maintain operation of SRM under light load condition.

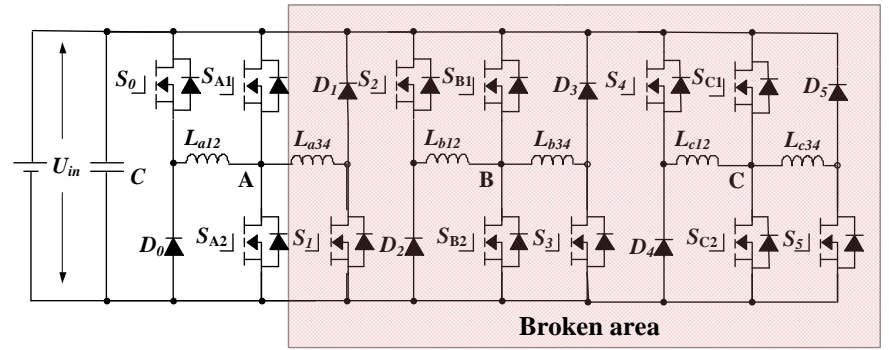

Fig. 11. Extreme faulty operations.
A comparison of the proposed fault tolerance topology and existing fault tolerance methods is illustrated in Table I. It can be seen that the proposed method has a better overall performance, which will be proved in the following sections.

TABLE I THE PROPOSED FAULT TOLERANCE TOPOLOGY COMPARING WITH OTHER FAULT TOLERANCE METHODS

\begin{tabular}{|c|c|c|c|c|}
\hline & Proposed method & $\begin{array}{c}\text { Traditional SRM } \\
\text { system [13] }\end{array}$ & $\begin{array}{c}\text { Specially designed } \\
\text { motor [25][27] }\end{array}$ & $\begin{array}{c}\text { Fault tolerance topology } \\
\text { Paper [29] }\end{array}$ \\
\hline Motor structure & Traditional SRM & Traditional SRM & Special design & Special design \\
\hline Fault diagnosis & Easy & Complicated & N/A & Easy \\
\hline Fault tolerance & $\begin{array}{c}\text { Achievable } \\
\text { without phase } \\
\text { absence }\end{array}$ & $\begin{array}{c}\text { Achievable } \\
\text { with phase absence }\end{array}$ & $\begin{array}{c}\text { Achievable } \\
\text { with phase absence }\end{array}$ & $\begin{array}{c}\text { Achievable } \\
\text { without phase } \\
\text { absence }\end{array}$ \\
\hline wodular structure & Yes & Yes & Yes & Yes \\
\hline Cost & Medium & Low & High & High \\
\hline $\begin{array}{c}\text { Operation at } \\
\text { extreme faults }\end{array}$ & Achievable & No & Achievable & Achievable \\
\hline
\end{tabular}

\section{Design Procedure}

There are three basic steps in the system design procedure.

(1) Developing key parameters and application specifications, including rated power, torque, supply voltage, rated speed, speed range and efficiency, design switched reluctance motor [3].

(2) Building SRM simulation models in Ansoft to check the electromagnetic performance, and optimizing key parameters.

(3) Converter design in relation to SRM working condition. By building SRM models and converter models in Matlab/Simulink, The starting, braking, rated power operation and over power operation are simulated to support for switching device selection. The fault tolerance topology chooses the same switching devices with the main driving topology.

\section{Phase Current Sensor Placement Strategy}

The phase current is the main source of information for fault diagnosis and fault tolerance operation. In the proposed fault tolerance topology, the current sensor placement strategy is studied considering the cost and modular structure.

\section{Single Current Sensor Placement Strategy}

Current sensors are expensive and need extra A/D channels to transfer analog signal to digital signals for controller so that the system cost is increased. The single current sensor is one of the best choices. Traditional current sensor strategy is illustrated in Fig. 12; there are four candidate placement positions, but none of them can give the phase current signal both under left part and right part phase converter fault condition.

Fig.13 (a) is the proposed current sensor placement strategy. The number of turns in both sides from the point $\mathrm{A}$ is the same. In normal condition, there is no current passing point $\mathrm{A}$, as shown in Fig. 13 (b). The current sensor output is the sum of $i_{\text {Lal2 }}$ and $i_{\text {La34 }}$. When right part of phase converter is fault, by the fault tolerance operation, the right part is shorted by the half bridge switching devices; the output of current sensor is $i_{\text {Lal2 }}$, as shown in Fig. 13 (c). When left part of phase converter is fault, by the fault tolerance operation, the left part is shorted by the half bridge switching devices; the output of current sensor is $i_{\text {La34 }}$, as illustrated in Fig. 13 (d). The output of current sensor signal magnification times is only half the normal condition. Compared with the traditional sensor placement strategy, the proposed method can give the phase current information at fault tolerance operation condition.

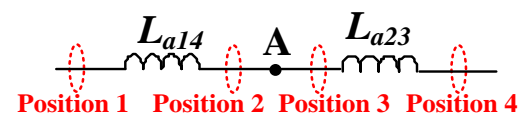

Fig. 12. Traditional current sensor placement strategy.

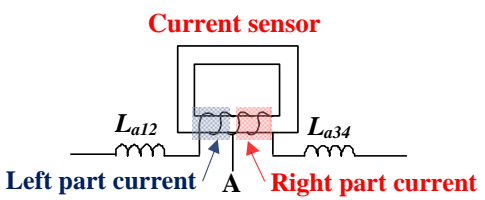

(a) Proposed single current sensor placement strategy

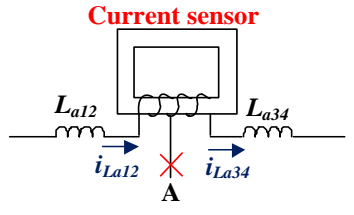

(b) Normal condition 


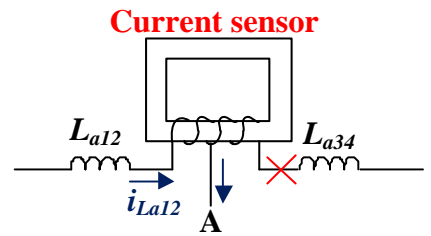

(c) Right part fault condition

Fig. 13. Proposed single current placement strategy.

\section{E. Dual Current Sensor Placement Strategy}

Fig. 12 shows the current placement strategy. Although the number of current sensors is decreased, the output of sensor signal magnification times is also changed when fault occurs that may be inconvenient for controller. Furthermore, the Fig.13 strategy does not have the characteristics of modulation.

Dual sensors can give the separate signals of both left part and right part of phase winding current. Fig.14 (a) is the basic structure of dual current placement strategy. On the whole structure, Fig. 14 (a) does not have the characteristics of modular. Because current commercial drive mode for SRM has combined one current sensor for each phase and half bridge drive topology as the standard configuration. Fig. 14 (b) gives another solution. The current placement strategy in main drive topology is the same as usual; the other current sensor is in fault tolerance part. In a normal condition, the current sensors $\mathrm{CS}_{\mathrm{A}}$, $\mathrm{CS}_{\mathrm{B}}$ and $\mathrm{CS}_{\mathrm{C}}$ give the phase current information. When fault occurs, the current sensors $\mathrm{CS}_{\mathrm{A} 1}, \mathrm{CS}_{\mathrm{B} 1}$ and $\mathrm{CS}_{\mathrm{C} 1}$ give the phase current information in fault tolerance operation. Because the main drive topology and its current sensor compose a relative independent system; the fault tolerance topology and its corresponding current sensors also have relative independence. Due to the modular and independence characteristics, the proposed fault tolerance strategy can be used in the current SRM system without any hardware change.

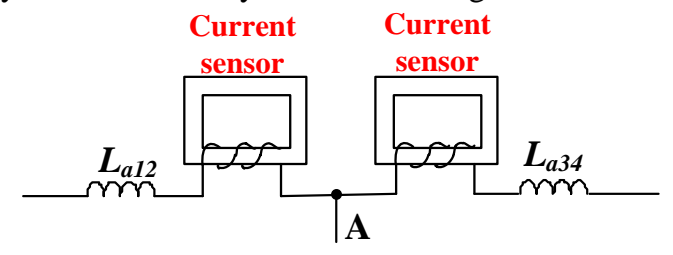

(a) Dual current sensor placement strategy

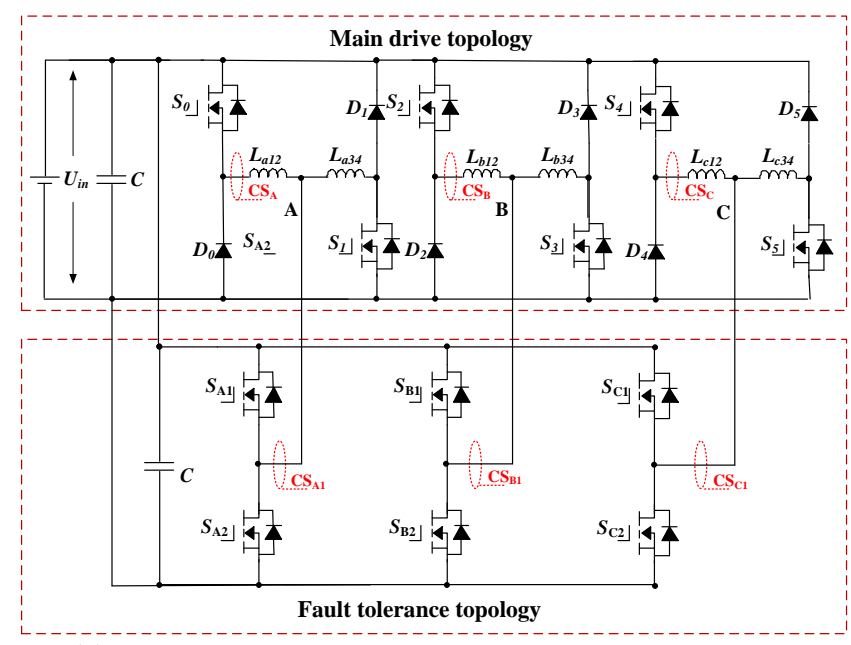

(b) Proposed dual current sensor placement strategy

Fig. 14. Dual current placement strategy.

\section{SIMULATION AND EXPERIMENT}

In order to validate the proposed fault tolerance topology, a $750 \mathrm{~W} 12 / 8 \mathrm{SRM}$ is employed to be modeled in the Matlab/Simulation. The SRM control system is developed in Matlab/Simulink, as shown in Fig. 15. The rotor position is obtained by a position calculator from the angular velocity. The converter is built by using the models in the SimPowerSystems. The velocity is calculated according to the total torque exporting from the phase model and the load torque. The switching controller is used to give the gate signals according to the given speed, instantaneous speed, turn-on angle and turn-off angle. Every phase current and torque can be observed directly in different simulation conditions.

TABLE II MOTOR PARAMETERS

\begin{tabular}{|c|c|}
\hline Parameters & Value \\
\hline Phase number & 3 \\
\hline Stator poles & 12 \\
\hline Rotor poles & 8 \\
\hline Rated speed (r/min) & 1500 \\
\hline Rated power $(\mathrm{W})$ & 750 \\
\hline Phase resistor $(\Omega)$ & 3.01 \\
\hline Minimum phase inductance $(\mathrm{mH})$ & 27.2 \\
\hline Maximum phase inductance $(\mathrm{mH})$ & 256.7 \\
\hline Rotor outer diameter $(\mathrm{mm})$ & 55 \\
\hline Rotor inner diameter $(\mathrm{mm})$ & 30 \\
\hline Stator outer diameter $(\mathrm{mm})$ & 102.5 \\
\hline Stator inner diameter $(\mathrm{mm})$ & 55.5 \\
\hline Core length $(\mathrm{mm})$ & 80 \\
\hline Stator arc angle $(\mathrm{deg})$ & 14 \\
\hline Rotor arc angle $(\mathrm{deg})$ & 16 \\
\hline
\end{tabular}

Fig. 16 shows the voltage-PWM control mode at $500 \mathrm{r} / \mathrm{min}$ under normal and fault conditions, respectively. The turn-on angle is set to $0^{\circ}$ and the turn-off angle to $20^{\circ}$. The load torque is set to $1 \mathrm{~N} \cdot \mathrm{m}$. In the simulation results, $i_{\mathrm{a}}, i_{\mathrm{b}}$, and $i_{\mathrm{c}}$ represent for phase A, B, and C current, respectively. $T$ and $T^{*}$ represent for the instantaneous torque and given load torque, respectively. When the drive operates in the normal state, the three phase currents have the same shape with $15^{\circ}$ phase-shift compare to each other, and the total torque is the sum of three phase torque, as shown in Fig. 16 (a). Due to the independence of each phase leg, the fault phase will not affect the other normal phase. For example of phase A, when an open-fault happens, phase A current declines to zero, and the torque is only the sum of phase $\mathrm{B}$ and $\mathrm{C}$ torque. In a closed-loop system, when the open-fault happens, the other two phase currents are excited to be larger than the previous one by increasing the PWM duty-cycle, to compensate the absent phase torque. However, the torque ripple gets larger than that in normal conditions, as shown in Fig. 16 (b). When a short-fault happens in upper-switch of phase $\mathrm{A}$, the phase voltage cannot be regulated in phase turn-on region, and the demagnetization current also cannot flow to power supply in the phase turn-off region, as shown in Fig. 16 (c). In this fault state, phase A current is obviously larger than the normal phase, causing the torque ripple. 


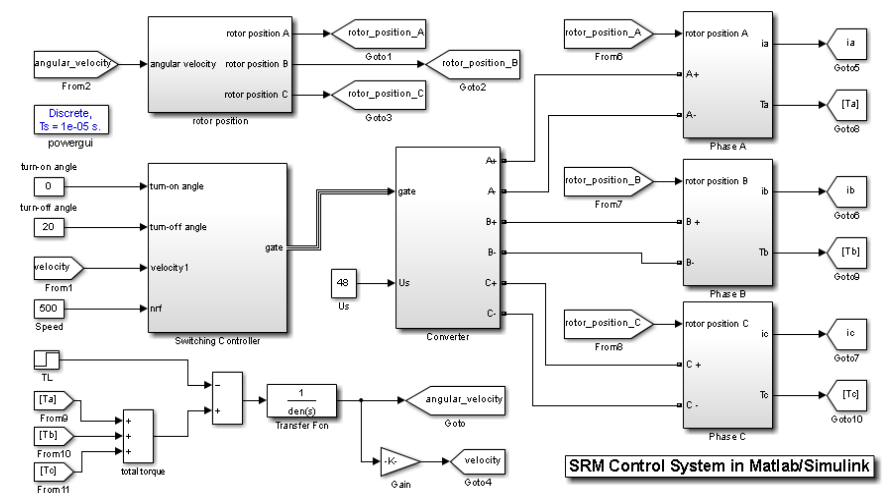

Fig. 15. SRM control system in Matlab/Simulink.

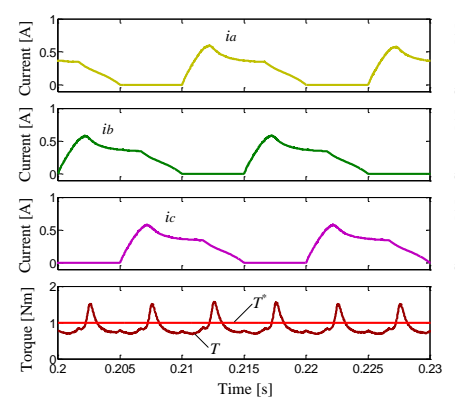

(a) Normal condition

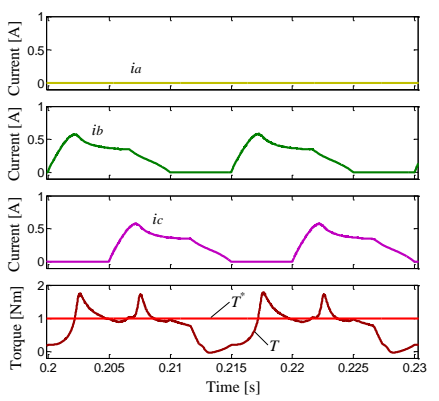

(b) Open fault
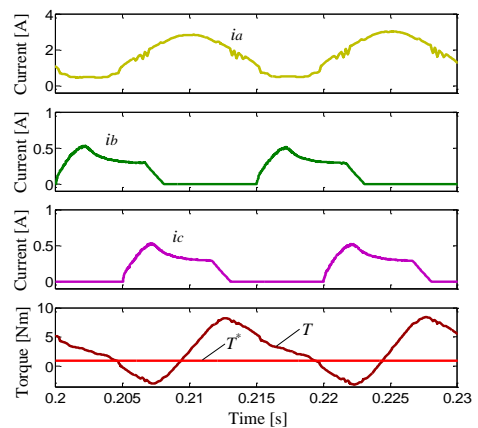

(c) Short fault

Fig. 16. Simulation results of voltage-PWM control mode under normal and fault conditions.

Fig. 17 shows the voltage-PWM control mode at $500 \mathrm{r} / \mathrm{min}$ with fault tolerance topology under fault condition. The additional three-phase half-bridge is put into use, no matter an open-fault or short fault is detected. As illustrated in Fig. 17 (a), the current slope and peak value of phase $\mathrm{A}$ in the initial conduction region are double of the normal value, based on the analysis above. Despite using the fault tolerant topology, the torque ripple and unbalanced degree of phase current are still large. In order to reduce them effectively, a fault tolerant scheme that lagging the turn-on angle of the fault phase is carried out, as shown in Fig. 17 (b). The turn-on angle is set to $5^{\circ}$ for phase $\mathrm{A}$, and the torque ripple is clearly reduced compared to Fig. 17 (a).
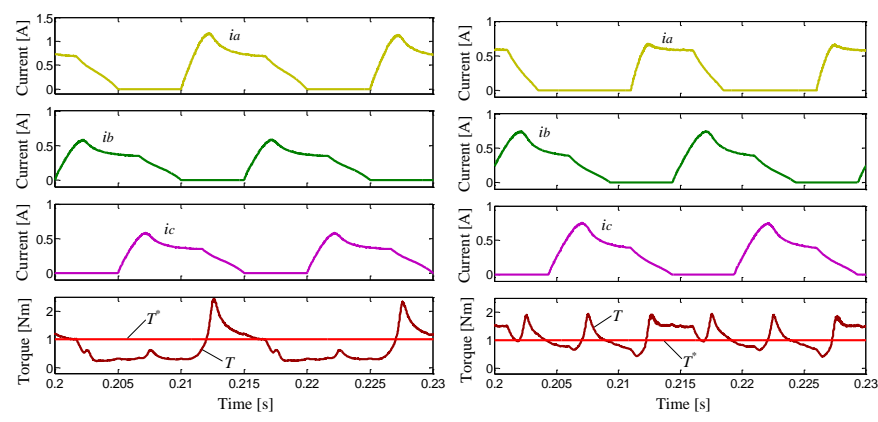

(a) Turn-on angle is $0^{\circ}$ for phase $A$

(b) Turn-on angle is $5^{\circ}$ for phase $A$ Fig. 17. Simulation results of voltage-PWM control mode with fault tolerance topology under fault conditions.

Fig. 18 shows the current regulation control mode under normal and faulty conditions, respectively. As shown in Fig. 18 (a), the torque ripple is smaller than that of voltage-PWM control mode in normal condition. The results under open and short-fault conditions are similar to the voltage-PWM control mode, as shown in Fig. 18 (b) and (c). Fig. 19 shows the fault tolerance results in current regulation control mode at $500 \mathrm{r} / \mathrm{min}$. In current regulation control system, phase current is the control target, and it is regulated to the same reference compared to the normal one. The only differences are the current slope. The torque ripple is effectively reduced to the normal one compared to Fig. 18 (a), if the fault tolerance topology is adopted.

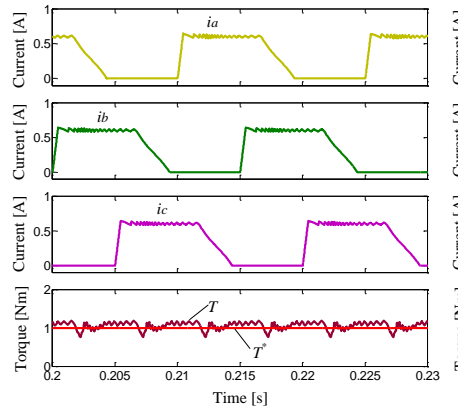

(a) Normal

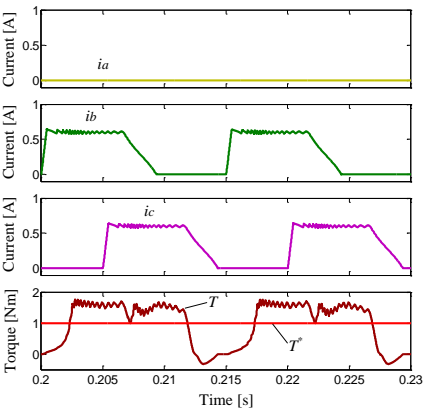

(b) Open fault

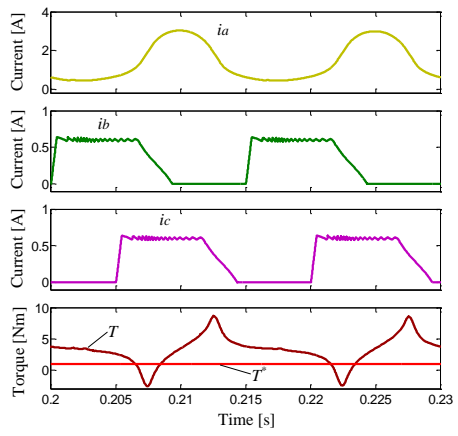

(c) Short fault

Fig. 18. Simulation results of current regulation control mode with fault tolerance topology under fault conditions. 


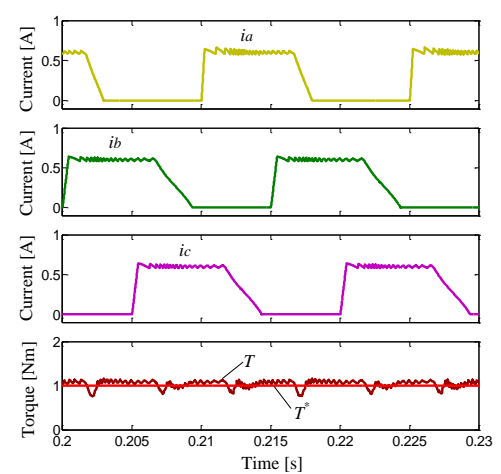

Fig. 19. Simulation results of current regulation control mode with fault tolerance topology under fault conditions.

To verify the effectiveness of the propose scheme experimentally, an experimental rig for testing a $750 \mathrm{~W}$ SRM prototype is set up, as shown in Fig. 20(a). Photographs of the employed current sensors are shown in Fig. 20(b). Two air switches are adopted to emulate open-circuit and short-circuit faults, as shown in Fig. 20(c), where $J_{1}$ is used to achieve an open circuit fault and $J_{2}$, a short circuit fault. The main motor parameters are illustrated Table II. Fig. 20(d) shows the fault tolerance control system diagram with the closed-loop speed regulation capability. As illustrated in the figure, a PI controller is used to regulate the motor speed, and the proportional gain and integral gain are 0.05 and 0.5 , respectively. The current controller and voltage controller are utilized to generate the drive signals to control the motor drive in different operation modes. The position detector and speed calculator are used to give the instantaneous speed for feedback control. The current sampling and fault diagnosis schemes are employed to control the gate signals for the fault tolerance topology to operate under faulted conditions.

The type of the used MOFESTs is FDA59N30 from Fairchild Inc; and diodes are IDW75E60 from Infineon Technologies. Three current sensors (LA55Ps) are used to measure the phase currents. An incremental encoder with 1000 lines is used to measure the rotor position. A dSPACE 1006 control board is employed to implement the control scheme, with its control diagram shown in Fig. 21(a) and flowcharts in Fig. 21(b) and (c). A magnetic brake acts as the load with a torque of $1 \mathrm{~N} \cdot \mathrm{m}$. The dc-link voltage is fixed to $48 \mathrm{~V}$. Two air switches are adopted to generate open-circuit and short-circuit faults. The torque observed in the oscilloscope is obtained online by using the real-time phase currents and rotor position to look up for the torque value in a 3-D torque table that includes the $T-i-\theta$ characteristics [33], [34]. The torque data in the lookup table is measured by using a rotor clamping device when supplying different steady currents to the motor windings in a rotor position that changes step by step. The output torque in the experimental waveforms is observed though a D/A converter.

The turn-on and turn-off angles are set to $0^{\circ}$ and $20^{\circ}$. In voltage-PWM control system with fault tolerance topology, the turn-on angle is set to $5^{\circ}$ to improve the phase current balance for the fault tolerance performance when the short-fault occurs. Figs. 22-25 present the experimental results at $500 \mathrm{r} / \mathrm{min}$, where $i_{a}, i_{b}$, and $i_{c}$ are the phase currents for phase $\mathrm{A}, \mathrm{B}$ and $\mathrm{C}$, respectively; $T^{*}$ and $T$ are the given load torque and instantaneous torque, which show a good agreement with the simulation results. Fig. 22 presents the typical voltage-PWM control model waveforms of the SRM under normal, open-circuit fault, and short-circuit fault conditions. In a normal condition, three phases have the same current amplitude and shape. In an open circuit faulty condition, there is no current in the faulty phase. In a short circuit faulty condition, the faulty phase current cannot decrease to zero. The experiment results have agreed well with the analytical study in Section II. Fig. 23 verifies the control strategy under fault condition. By controlling the turn-on angle of phase A, the output torque ripple can be decreased obviously. Fig. 24 shows the typical waveforms for the current regulation control model under normal, open fault, and short fault condition. In an open circuit faulty condition, there is no current in the faulty phase whilst in a short circuit faulty condition, as theory analysis, the fault phase current cannot decrease to zero. The experiment results also verify the theory analysis in Section II. Under these fault tolerance operation conditions, the faulty phase current and output torque with the proposed method can follow the reference values faithfully, as shown in Fig.25. This is also the case in reducing the torque ripple and the imbalance between phase currents for conventional converters with either open-circuit or short-circuits faults.

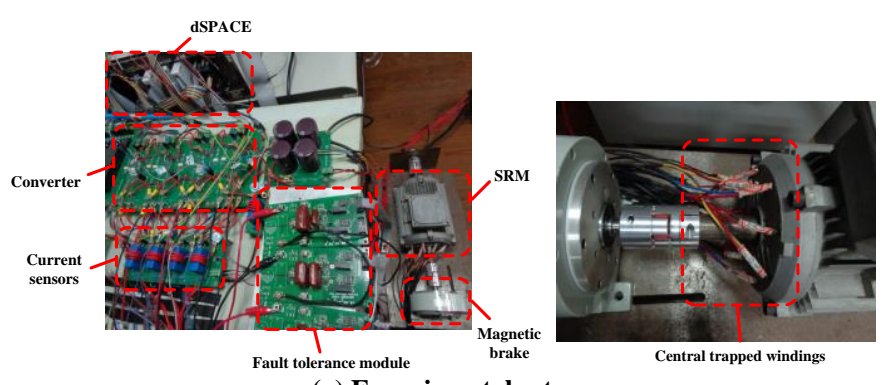

(a) Experimental setup

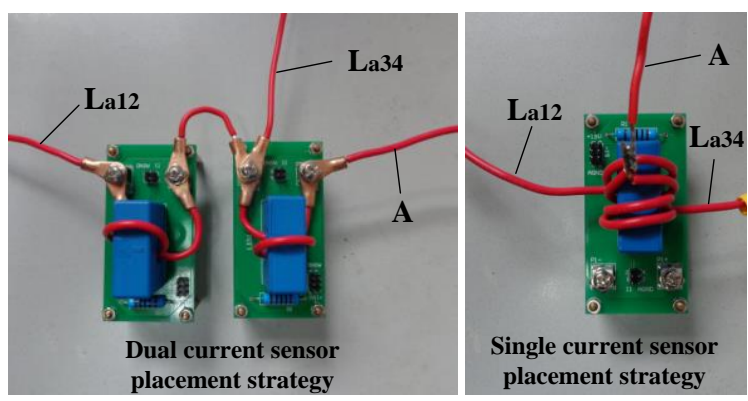

(b) Details of the two current sensors placement method

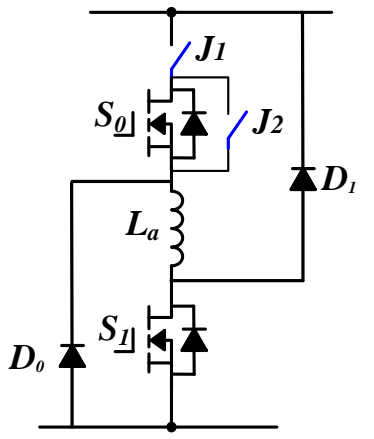

(c) Generation of faults by $J_{1}$ and $J_{2}$ 


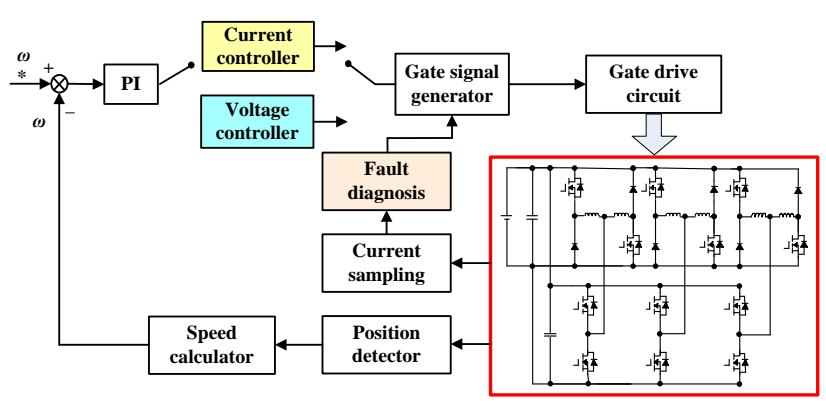

(d) Diagram of the fault tolerance control system

Fig. 20. Experimental setup and the control system.

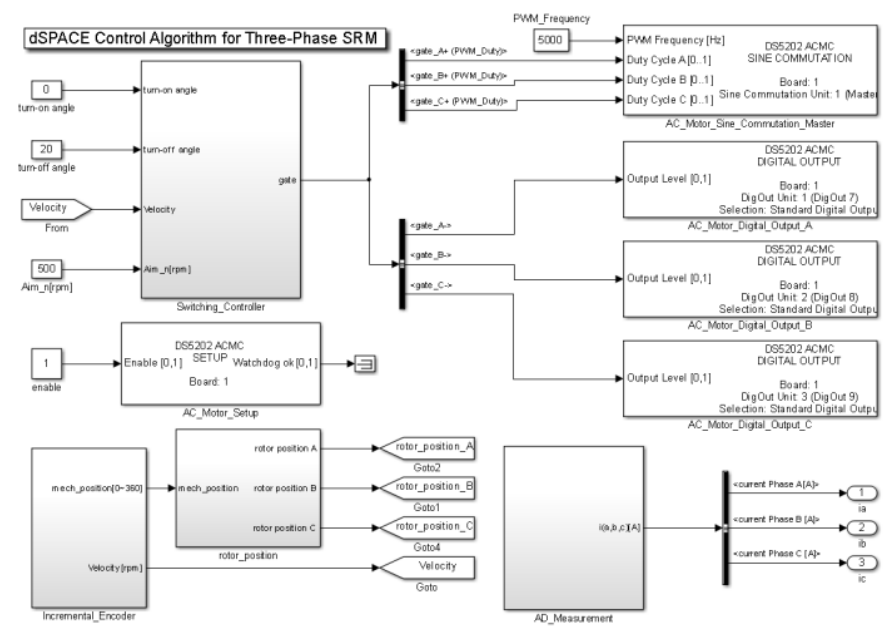

(a) dSPACE control diagram

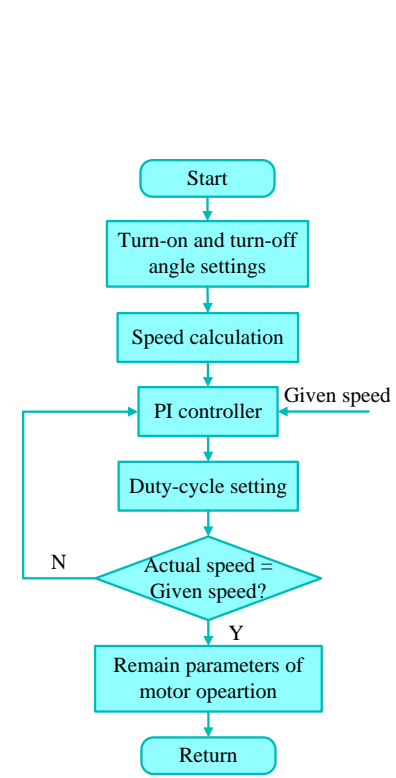

(b) Flowchart of algorithm for voltage-PWM control

\section{Fig. 21. dSPACE control algorithm.}

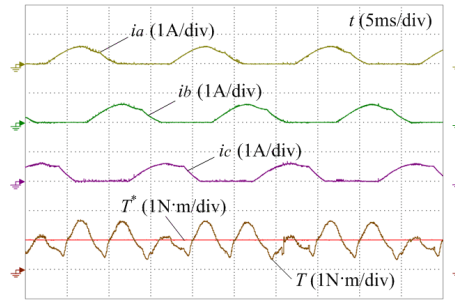

(a) Normal

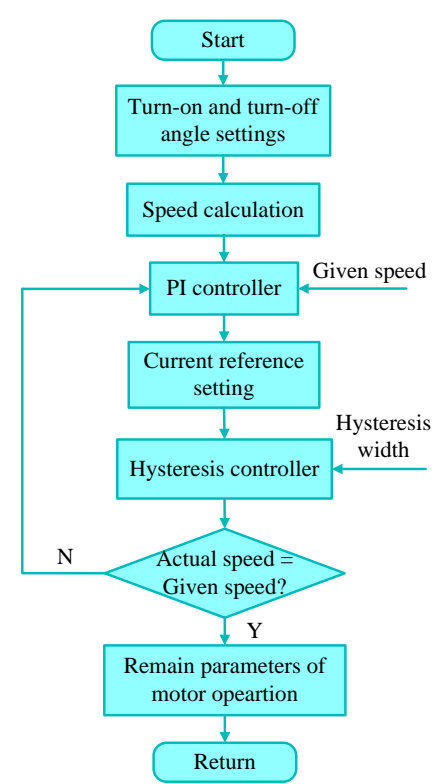

(c) Flowchart of algorithm

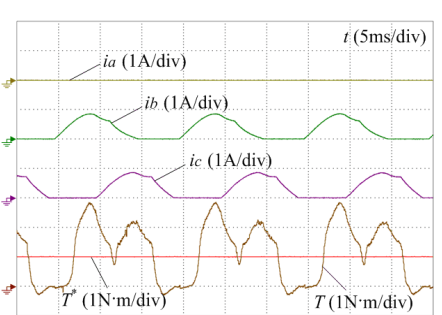

(b) Open fault for current regulation control

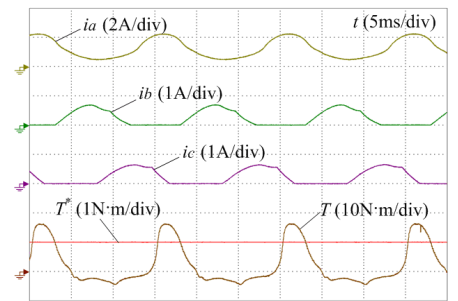

(c) Short fault

Fig. 22. Experimental results of voltage-PWM control mode under normal and fault conditions.
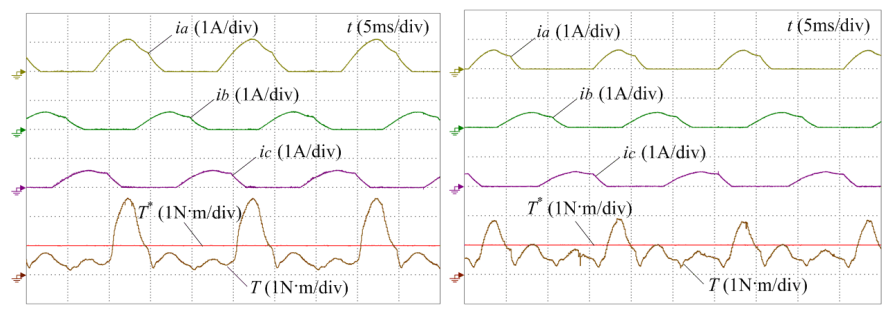

(a) Turn-on angle is $0^{\circ}$ for phase $A$ (b) Turn-on angle is $5^{\circ}$ for phase $A$ Fig. 23. Experimental results of voltage-PWM control mode with fault tolerance topology under fault conditions.

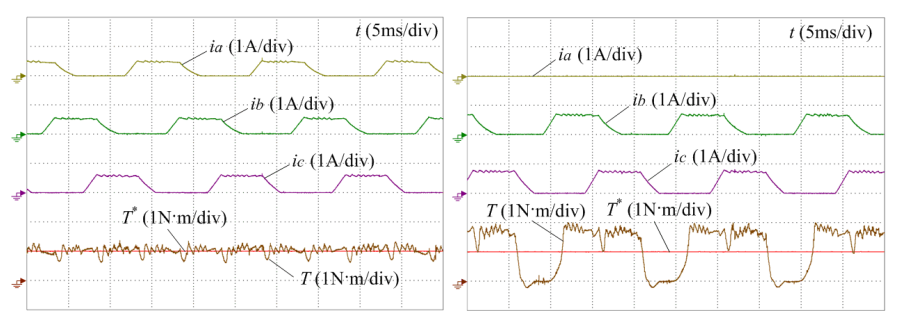

(a) Normal

(b) Open fault

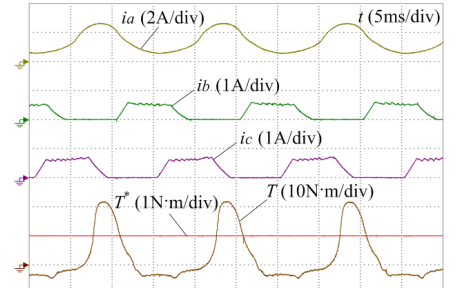

(c) Short fault

Fig. 24. Experimental results of current regulation control mode with fault tolerance topology under fault conditions.

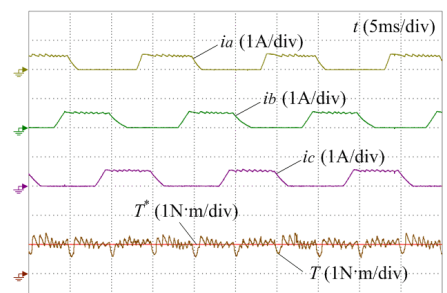

Fig. 25. Experimental results of current regulation control mode with fault tolerance topology under fault conditions.

Fig. 26 shows the fault tolerance operation at $500 \mathrm{r} / \mathrm{min}$ and 5 $\mathrm{N} \cdot \mathrm{m}$ load in CCC and PWM systems, respectively. The system can still be stable when operating at large load and make up for the missing output torque of the fault phase. Fig. 27 shows the operation of the developed system during acceleration and at high speeds with a $1 \mathrm{~N} \cdot \mathrm{m}$ load. As illustrated in Fig. 27(a), the speed follows the given value well during the continuous acceleration progress. In Fig. 27(b), the system is still stable when it is operated at $1500 \mathrm{r} / \mathrm{min}$, which shows a good stability at high speed. 


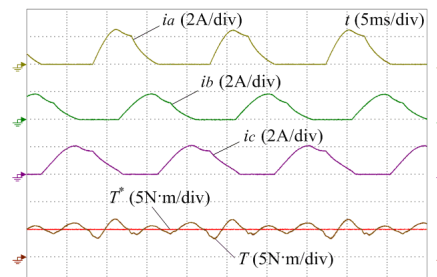

(a) PWM system

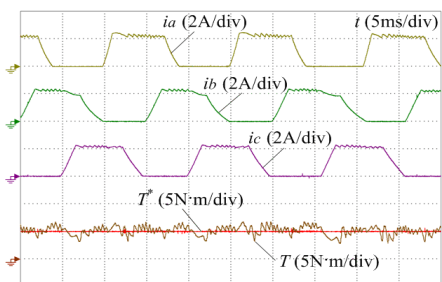

(b) CCC system
Fig. 26. Experimental results of fault tolerance operation under the high load.

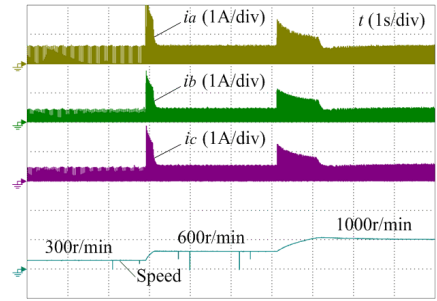

(a) Acceleration

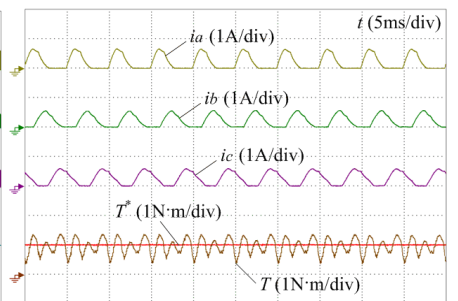

(b) High speed operation
Fig. 27. Experimental results of fault tolerant operation during acceleration and at high speed operation.

Fig. 28 shows the fault tolerance operation with only a half phase winding at $500 \mathrm{r} / \mathrm{min}$ and $1 \mathrm{~N} \cdot \mathrm{m}$ load in CCC and PWM systems, respectively. The system can still operate with only a half phase winding at light load. Fig. 29 shows the fault tolerance operation with only a half phase winding during acceleration and load increasing. The speed still follows the given speed well no matter during acceleration and in steady state. However, in Fig. 29(b), when the load increases from 1 $\mathrm{N} \cdot \mathrm{m}$ to $3 \mathrm{~N} \cdot \mathrm{m}$, the speed is reduced due to the insufficient load ability. Hence, in the extreme faulty conditions, the proposed fault tolerance scheme can still operate at light loads.

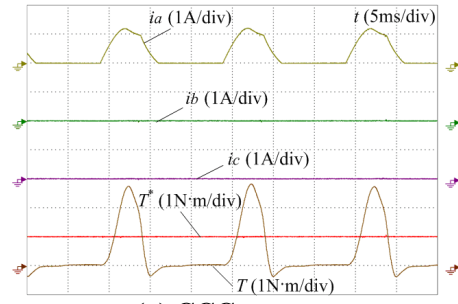

(a) CCC system

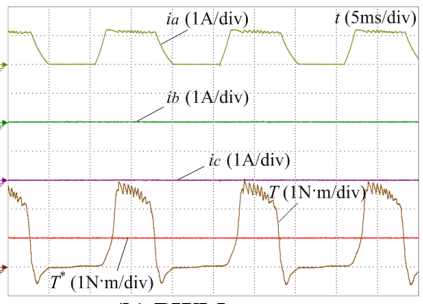

(b) PWM system
Fig. 28. Experimental results of fault tolerance operation with only a half phase winding in the extreme faulty condition at steady-state operation.

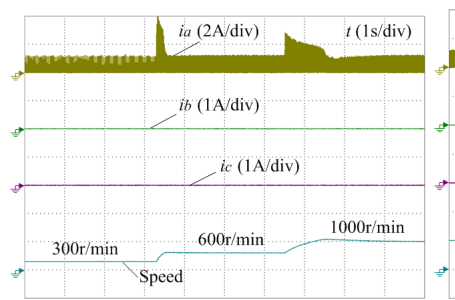

(a) Acceleration

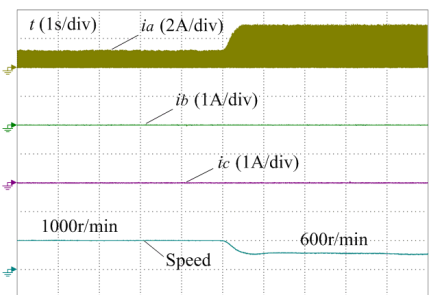

(b) Load increasing
Fig. 29. Experimental results of fault tolerance operation with only a half phase winding during acceleration and load increasing.

\section{CONCLUSION}

In this paper, a central-tapped node linked modular fault tolerance topology is proposed for SRM-based EV applications, based on the axial symmetrical structure of the phase converter. The main contributions of this paper are: (i) a novel fault tolerance SRM topology is developed with a modular structure; (ii) fault diagnosis and the corresponding fault tolerance architecture are proposed to achieve convenient fault diagnosis and improve fault tolerance performance of the SRM; (iii) two current sensor placement strategies are also developed to achieve low cost and modular structure.

By combining the modular SRM fault tolerance structure with the central tapped node, the fault in the phase converter can be diagnosed easily; the faulty part can be blocked by the fault tolerance topology to achieve fault tolerance operation. Furthermore, the proposed system is in an idle condition when the SRM drive is healthy. The modular topology can be added to the traditional SRM drives without much change to the circuitry. The proposed current sensor placement strategy offers a low-cost and modular solution to typical power switch faults. The developed technologies can be applied to high-reliability drive applications such as electric vehicles, ships and aerospace.

\section{REFERENCES}

[1] B. K. Bose, "Global energy scenario and impact of power electronics in 21st century," IEEE Trans. Ind. Electron., vol. 60, no. 7, pp. 2638-2651, Jul. 2013.

[2] Y. Hu, X. Song, W. Cao, and B. Ji, "New SR drive with integrated charging capacity for plug-in hybrid electric vehicles (PHEVs)," IEEE Trans. Ind. Electron., vol. 61, no. 10, pp. 5722-5731, Oct. 2014.

[3] Miller T. J. E. "Switched reluctance motors and their control," London: Magna Physics Publishing and Oxford Science, 3-25, 1993.

[4] J. Liang, D. H. Lee, G. Xu, J. W. Ahn, "Analysis of passive boost power converter for three-phase SR drive," IEEE Trans. Ind. Electron., vol. 57, no. 9, pp. 2961-2971, Sep. 2010.

[5] D. H. Lee, T. H. Pham, J. W. Ahn, "Design and operation characteristics of four-two pole high-speed SRM for torque ripple reduction," IEEE Trans. Ind. Electron., vol. 60, no. 9, pp. 3637-3643, Sep. 2013.

[6] L. Shen, J. Wu, and S. Yang, "Initial position estimation in SRM using bootstrap circuit without predefined inductance parameters," IEEE Trans. Power Electron., vol. 26, no. 9, pp. 2449-2456, Sep. 2011.

[7] A. G. Jack, B. C. Mecrow, and J. A. Haylock, "A comparative study of permanent magnet and switched reluctance motors for high-performance fault-tolerant applications," IEEE Trans. Ind. Appl., vol. 32, no. 4, pp. 889-895, Jul./Aug. 1996.

[8] S. Gopalakrishnan, A. M. Omekanda, and B. Lequesne, "Classification and remediation of electrical faults in the switched reluctance drive," IEEE Trans. Ind. Appl., vol. 42, no. 2, pp. 479-486, Mar/Apr. 2006.

[9] B. Ji, V. Pickert, W. Cao, and B. Zahawi, "In situ diagnostics and prognostics of wire bonding faults in IGBT modules for electric vehicle drives," IEEE Trans. Power Electron., vol. 28, no. 12, pp. 5568-5577, Dec. 2013.

[10] H. Torkaman, E. Afjei, and P. Yadegari, "Static, dynamic, and mixed eccentricity faults diagnosis in switched reluctance motors using transient finite element method and experiments," IEEE Trans. Magn., vol. 48, no. 8, pp. 2254-2264, Aug. 2012.

[11] N. S. Gameiro, and A. J. Marques Cardoso, "A new method for power converter fault diagnosis in SRM drives," IEEE Trans. Ind. Appl., vol. 48, no. 2, pp. 653-662, Mar./Apr. 2012.

[12] C. Hao, and L. Shengli, "Fault diagnosis digital method for power transistors in power converters of switched reluctance motors," IEEE Trans. Ind. Electron., vol. 60, no. 2, pp. 749-763, Feb. 2013.

[13] J. F. Marques, J. O. Estima, N. S. Gameiro, and A. M. Cardoso, "A new diagnostic technique for real-time diagnosis of power converter faults in switched reluctance motor drives," IEEE Trans. Ind. Appl., vol. 50, no. 3, pp. 1854-1860, May/Jun. 2014.

[14] N. S. Gameiro, and A. J. M. Cardoso, "Fault tolerant control strategy of SRM drives," IEEE International Symposium on Power Electronics, Electrical Drives, Automation and Motion, Ischia, Italy, pp. 301-306, Jun. 2008.

[15] A. A. Arkadan, P. Du, M. Sidani, and M. Bouji, "Performance prediction of SRM drive systems under normal and fault operating conditions using 
GA-based ANN method," IEEE Trans. Magn., vol. 36, no. 4, pp. 1945-1949, July. 2000.

[16] M. Bouji, A. A. Arkadan, and T. Ericsen, "Fuzzy inference system for the characterization of SRM drives under normal and fault conditions," IEEE Trans. Magn., vol. 37, pp. 3745-3748, Sep. 2001.

[17] A. A. Arkadan, and B. W. Kielgas, "Switched reluctance motor drive systems dynamic performance prediction under internal and external fault conditions," IEEE Trans. Energy Convers., vol. 9, no. 1, pp. 45-52, Mar. 1994.

[18] B. Lequesne, S. Gopalakrishnan, and A. M. Omekanda, "Winding short circuits in the switched reluctance drive," IEEE Trans. Ind. Appl., vol. 41, no. 5, pp. 1178-1184, Sep/Oct. 2005.

[19] H. Torkaman, and E. Afjei, "Comprehensive detection of eccentricity fault in switched reluctance machines using high-frequency pulse injection," IEEE Trans. Power Electron., vol. 28, no. 3, pp. 1382-1390, Mar. 2013.

[20] L. A. Belfore, II, and A. Arkadan, "A methodology for characterizing fault tolerant switched reluctance motors using neurogenetically derived models," IEEE Trans. Energy Convers., vol. 17, no. 3, pp. 380-384, Sep. 2002.

[21] S. Mir, M. S. Islam, T. Sebastian, and I. Husain, "Fault-tolerant switched reluctance motor drive using adaptive fuzzy logic controller," IEEE Trans. Power Electron., vol. 19, no. 2, pp. 289-295, Mar. 2004.

[22] M. D. Hennen, M. Niessen, C. Heyers, H. J. Brauer, and R. W. De Doncker, "Development and control of an integrated and distributed inverter for a fault tolerant five-phase switched reluctance traction drive," IEEE Trans. Power Electron., vol. 27, no. 2, pp. 547-554, Feb. 2012.

[23] A. Labak, and N. C. Kar, "Designing and prototyping a novel five-phase pancake-shaped axial-flux SRM for electric vehicle application through dynamic FEA incorporating flux-tube modeling," IEEE Trans. Ind. Appl., vol. 49, no. 3, pp. 1276-1288, May/Jun. 2013.

[24] W. Ding, Y. Liu, Y. Hu, "Performance evaluation of a fault-tolerant decoupled dual-channel switched reluctance motor drive under open-circuits," IET Electric Power Applications, vol. 8, no. 4, pp. 117-130, Apr. 2014.

[25] M. Ruba, I. A. Viorel, Szabo, x, and L., "Modular stator switched reluctance motor for fault tolerant drive systems," IET Electric Power Applications, vol. 7, no. 3, pp. 159-169, Mar. 2013.

[26] H. Torkaman, E. Afjei, and M. S. Toulabi, "New double-layer-per-phase isolated switched reluctance motor: concept, numerical analysis, and experimental confirmation," IEEE Trans. Ind. Electron., vol. 59, no. 2, pp. 830-838, Feb. 2012.

[27] L. Szabo, and M. Ruba, "Segmental stator switched seluctance machine for safety-critical applications," IEEE Trans. Ind. Appl., vol. 48, no. 6, pp. 2223-2229, Nov./Dec. 2012.

[28] N. S. Gameiro, A. J. M. Cardoso, "Fault Tolerant Power Converter for Switched Reluctance Drives," $18^{\text {th }}$ International Conference on Electrical Machines, Algarve, Portugal, pp. 1-6, Sep. 2008.

[29] M. Ruba, C. Oprea, L. Szabó, "Comparative Study on Switched Reluctance Machine Based Fault-Tolerant Electrical Drive Systems," IEEE International Conference on Electric Machines and Drives 2009, Miami, USA, pp.987-992, May 2009.

[30] W. Wang, B. Fahimi, "Fault resilient strategies for position sensorless methods of switched reluctance motors under single and multiphase fault," IEEE Journal of Emerging and Selected Topics in Power Electronics, vol. 2, no. 2, pp. 190-200, Jun. 2014.

[31] A. C. Oliveira, C. B. Jacobina, A. M. N. Lima, and F. Salvadori, "Startup and fault tolerance of the SRM drive with three-phase bridge inverter," IEEE Conference in Power Electronics Specialists, 2005, Recife, Brazil, pp. 714-719, Jun. 2005.

[32] L. Xu, D. Zhao, C. Zhang, R. P. Ge, "Research on fault analysis and fault-tolerant control of valve electric actuator system based on SRM," International Symposium in Computational Intelligence and Design (ISCID), Hangzhou, China, pp. 389-393, Oct. 2012.

[33] D. H. Lee ; J. Liang ; Z. G. Lee ; J. W. Ahn, "A simple nonlinear logical torque sharing function for low-torque ripple SR drive," IEEE Trans. Ind. Electron., vol. 56, no. 8, pp. 3021-3028, Aug. 2009.

[34] V. P. Vujic, "Minimization of torque ripple and copper losses in switched reluctance drive," IEEE Trans. Power Electron., vol. 27, no. 1, pp. 388-399, Jan. 2012.

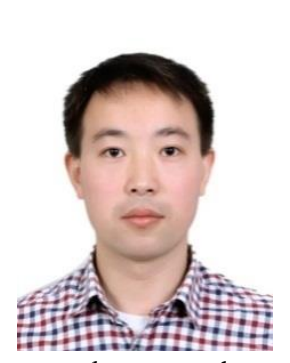

Yihua Hu (M'13) received the B.S. degree in electrical motor drives in 2003, and the Ph.D. degree in power electronics and drives in 2011, both from China University of Mining and Technology, Jiangsu, China. Between 2011 and 2013, he was with the College of Electrical Engineering, Zhejiang University as a Postdoctoral Fellow. Between November 2012 and February 2013, he was an academic visiting scholar with the School of Electrical and Electronic Engineering, Newcastle University, Newcastle upon Tyne, UK. He is currently a research associate with the Department of Electronic \& Electrical Engineering, University of Strathclyde, Glasgow, UK. He has published more than 50 technical papers in leading journals and conference proceedings. His research interests include PV generation system, power electronics converters $\&$ control, and electrical motor drives.

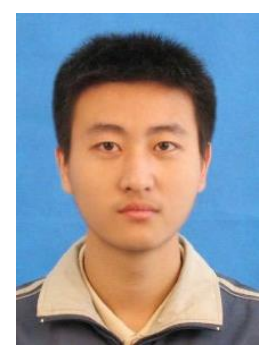

Chun Gan (S'14) received B.S. and M.S. degrees in power electronics and drives from China University of Mining and Technology, Jiangsu, China, in 2009 and 2012, respectively. He is currently working toward Ph.D. degree in the College of Electrical Engineering, Zhejiang University, Hangzhou, China. His research interests include electrical motor drives, motor design, control with emphasis on switched reluctance motor sensorless technique, and optimization of the torque ripple and efficiency of the motor system.

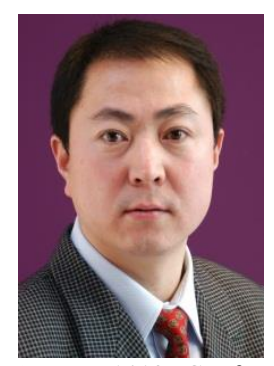

Wenping Cao (M’05-SM'11) received the B.Eng. in electrical engineering from Beijing Jiaotong University, Beijing, China, in 1991; and the Ph.D. degree in electrical machines and drives from the University of Nottingham, Nottingham, U.K., in 2004. He is currently a Senior Lecturer with Queen's University Belfast, Belfast, U.K. His research interests include thermal performance and fault analysis of electric machines, drives and power electronics.

Dr. Cao is the recipient of the Best Paper Award at the LDIA'13 Conference. He serves as an Associate Editor for IEEE TRANSACTIONS ON INDUSTRY APPLICATIONS, IEEE Industry Applications Magazine, IET Power Electronics, and nine other International Journals. He is also a member of the Institution of Engineering and Technology and a Fellow of Higher Education Academy.

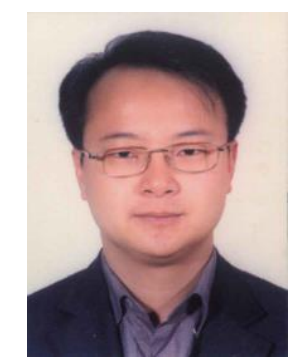

Wuhua Li (M'09) received the B.Sc. and Ph.D. degree in Applied Power Electronics and Electrical Engineering from Zhejiang University, Hangzhou, China, in 2002 and 2008, respectively. From September 2004 to March 2005, he was a Research Intern, and from January 2007 to June 2008, a Research Assistant in GE Global Research Center, Shanghai, China. From July 2008 to April 2010, he joined the College of Electrical Engineering, Zhejiang University as a Post doctor. In May 2010, he became a faculty member at Zhejiang University as a Lecturer. In December 2010, he was promoted as an Associate Professor. 
From July 2010 to September 2011, he was a Ryerson University Postdoctoral Fellow with the Department of Electrical and Computer Engineering, Ryerson University, Toronto, ON, Canada. His research interests include high efficiency power converters and renewable energy power conversion system. Dr. Li has published more than 100 peer-reviewed technical papers and holds over 20 issued/pending patents.

Due to his excellent teaching and research contributions, Dr. Li received the 2011 TOP TEN Excellent Young Staff Award and the 2012 Distinguished Young Scholar from Zhejiang University, the 2012 Outstanding Young Researcher Award from Zhejiang Province, the 2012 Delta Young Scholar from Delta Environmental \& Educational Foundation and the 2012 National Outstanding Young Scholar. He received three Scientific and Technological Achievements Awards from Zhejiang Provincial Government and the State Educational Ministry of China in 2009 and 2011, respectively.

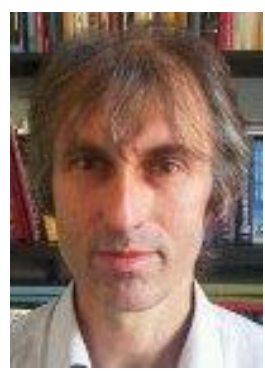

Stephen J. Finney received the M.Eng. degree from Loughborough University of Technology, Loughborough, U.K., in 1988 and the Ph.D. degree from Heriot-Watt University, Edinburgh, U.K., in 1995.For two years, he was with the Electricity Council Research Centre laboratories near Chester, U.K. He is currently a Professor with the University of Strathclyde, Glasgow, U.K. His areas of research interest are HVDC, MMC, renewable generation, and electrical vehicle. 